\title{
Influence of biofilm growth age, media, antibiotic concentration and exposure time on Staphylococcus aureus and Pseudomonas aeruginosa biofilm removal in vitro
}

\author{
Xiaofeng Chen ${ }^{1}$, Trine Rolighed Thomsen ${ }^{1,2}$, Heinz Winkler ${ }^{3}$ and Yijuan $\mathrm{Xu}^{1,2^{*}}$ (D)
}

\begin{abstract}
Background: Biofilm is known to be tolerant towards antibiotics and difficult to eradicate. Numerous studies have reported minimum biofilm eradication concentration (MBEC) values of antibiotics for many known biofilm pathogens. However, the experimental parameters applied in these studies differ considerably, and often the rationale behind the experimental design are not well described. This makes it difficult to compare the findings. To demonstrate the importance of experimental parameters, we investigated the influence of biofilm growth age, antibiotic concentration and treatment duration, and growth media on biofilm eradication. Additionally, OSTEOmycin ${ }^{\mathrm{TM}}$, a clinically used antibiotic containing allograft bone product, was tested for antibiofilm efficacy.

Results: The commonly used Calgary biofilm device was used to grow $24 \mathrm{~h}$ and $72 \mathrm{~h}$ biofilms of Staphylococcus aureus and Pseudomonas aeruginosa, which were treated with time-dependent vancomycin (up to $3000 \mathrm{mg} \mathrm{L}^{-1}$ ) and concentration-dependent tobramycin (up to $80 \mathrm{mg} \mathrm{L}^{-1}$ ), respectively. Two common bacteriological growth media, tryptic soy broth (TSB) and cation-adjusted Mueller Hinton broth (CaMHB), were tested. We found for both species that biofilms were more difficult to kill in TSB than in CaMHB. Furthermore, young biofilms ( $24 \mathrm{~h}$ ) were easier to eradicate than old biofilms (72 h). In agreement with vancomycin being time-dependent, extension of the vancomycin exposure increased killing of $\mathrm{S}$. aureus biofilms. Tobramycin treatment of $24 \mathrm{~h}$ P. aeruginosa biofilms was found concentration-dependent and time-independent, however, increasing killing was indicated for $72 \mathrm{~h} P$. aeruginosa biofilms. Treatment with tobramycin containing OSTEOmycin $T^{\mathrm{TM}}$ removed $72 \mathrm{~h}$ and $168 \mathrm{~h} P$. aeruginosa biofilms after 1 day treatment, while few $72 \mathrm{~h} \mathrm{~S}$. aureus biofilms survived after 2 days treatment with vancomycin containing OSTEOmycin $\mathrm{V}^{\mathrm{T}} \mathrm{M}$.
\end{abstract}

Conclusions: This study demonstrated biofilm removal efficacy was influenced by media, biofilm age and antibiotic concentration and treatment duration. It is therefore necessary to taking these parameters into consideration when designing experiments. The results of OSTEOmycin ${ }^{\mathrm{TM}}$ products indicated that simple in vitro biofilm test could be used for initial screening of antibiofilm products. For clinical application, a more clinically relevant biofilm model for the specific biofilm infection in question should be developed to guide the amount of antibiotics used for local antibiofilm treatment.

\footnotetext{
* Correspondence: xuyijuan@bio.aau.dk

${ }^{1}$ Center for Microbial Communities, Aalborg University, Aalborg East, Denmark

${ }^{2}$ Life Science Division, Danish Technological Institute, Aarhus, Denmark

Full list of author information is available at the end of the article
}

C C The Author(s). 2020 Open Access This article is licensed under a Creative Commons Attribution 4.0 International License, which permits use, sharing, adaptation, distribution and reproduction in any medium or format, as long as you give appropriate credit to the original author(s) and the source, provide a link to the Creative Commons licence, and indicate if changes were made. The images or other third party material in this article are included in the article's Creative Commons licence, unless indicated otherwise in a credit line to the material. If material is not included in the article's Creative Commons licence and your intended use is not permitted by statutory regulation or exceeds the permitted use, you will need to obtain permission directly from the copyright holder. To view a copy of this licence, visit http://creativecommons.org/licenses/by/4.0/ The Creative Commons Public Domain Dedication waiver (http://creativecommons.org/publicdomain/zero/1.0/) applies to the data made available in this article, unless otherwise stated in a credit line to the data. 


\section{Background}

To improve diagnosis, treatment and prevention of infections, it is necessary to differentiate between acute infections with primarily planktonic microorganisms and biofilm infections with overweight of clusters of microbial cells [1-4]. Most microorganisms in a biofilm grow slowly with down-regulated virulence and are heterogeneously distributed. They are less susceptible to antibiotics compared with their planktonic counterpart and can often not be cleared by the immune system [5-7]. Biofilm related infections can be device-related biofilm infections, such as prosthetic joint infections, or native tissue infections e.g. chronic osteomyelitis and cystic fibrosis. The current most effective treatment of biofilm related infections is to remove the infected medical device and to debride the infected tissue in combination with antibiotic therapy [8]. However, treatment failure is often, and many novel antibiofilm candidates are under research such as quorum sensing inhibitors, biofilm matrix degrading enzymes, and antimicrobial peptides.

An early and correct diagnosis is necessary for proper antibiotic administration. The minimum inhibitory concentration (MIC) is defined as the lowest concentration of the antibiotics preventing visible bacterial growth, while minimum bactericidal concentration (MBC) is the lowest concentration required to kill the bacteria. MICs are used by diagnostic laboratories mainly to confirm resistance. Determination of MIC and $\mathrm{MBC}$ is based on planktonic cells, whereas the minimum biofilm eradication concentration (MBEC) is defined as the lowest concentration of antibiotic required to eradicate the biofilm. MBEC has not been implemented in the clinical setting yet, and the published MBEC data are often incomparable because of different experimental conditions. Tables 1-2 illustrate examples of two important biofilm pathogens Staphylococcus aureus and Pseudomonas aeruginosa, and their MIC and MBEC values determined in several studies. As shown in Tables 1- 2, tryptic soy broth (TSB) and cation-adjusted Mueller Hinton broth (CaMHB) media are often used in these studies. TSB is a complex nutrient-rich general-purpose medium, while CaMHB is recommended for MIC testing of non-fastidious organisms according to ISO standard 20776-1: 2006 and is the standard medium in clinical laboratories in the US and European committee on antimicrobial susceptibility testing. High throughput methods for MBEC determination are most frequently used including 96-well microtiter plate combined with crystal violet staining, the Calgary biofilm device (CBD), or its commercial version the $\mathrm{MBEC}^{\mathrm{TM}}$ Assay (Innovotech, Canada) [23]. As shown in Table 1-2, MIC values were similar for most of the studies. However, MBEC of vancomycin towards $S$. aureus varies from 1 to more than $8000 \mathrm{mg}$ $\mathrm{L}^{-1}$. Similarly, the MBEC of tobramycin towards $P$. aeruginosa varies from 2 to $2560 \mathrm{mg} \mathrm{L}^{-1}$. This large discrepancy in MBEC values is surprising, especially in light of some studies using the same strain. We hypothesize that the different test parameters and lack of standardization contributed to the large disparity.

Biofilm infections such as prosthetic joint infections and chronic osteomyelitis are difficult to treat by oral or parenteral antibiotic therapy alone and debridement is needed for physical removal of biofilms [24, 25]. Management of orthopedic infections often involves use of local antibiotic impregnated cement after debridement to eradicate the potentially remaining planktonic bacteria and residues of biofilms. However, the applied antibiotic dose is often based on personal experiences of the surgeon as no recommendations are available regarding the amount of antibiotics to be used for spacer impregnation [26]. Despite of application of high doses, re-infections occur at $19 \%$ of cases [27]. Ideally, MBEC should be determined to guide the amount of antibiotics to be impregnated in the cement.

The purpose of this study was to demonstrate the influences of biofilm age, growth media, and antibiotics exposure time on $S$. aureus and $P$. aeruginosa biofilm removal using vancomycin (up to $3000 \mathrm{mg} \mathrm{L}^{-1}$ ) and tobramycin (up to $80 \mathrm{mg} \mathrm{L}^{-1}$ ), respectively. These two antibiotics were chosen because they are recommended for serious and life-threatening infections caused by Gram-positive bacteria and Gram-negative bacteria. TSB and CaMHB were chosen enabling comparison with studies in Tables 1 and 2. Four biofilm-forming strains were selected for this study. S. aureus strains DSM 110939 [28] was isolated from prosthetic knee infection while S. aureus ATCC 49230 was originally from chronic osteomyelitis. Both infections are known to be associated with biofilms. P. aeruginosa strain PA14 is a well-known biofilm former [29] and P. aeruginosa ATCC 15442 is also known to form biofilms [30,31]. In addition, we investigated the possibility of using simple in vitro biofilm test such as Calgary biofilm method as initial screening of antibiofilm product by testing OSTEOmycin ${ }^{\mathrm{TM}}$, an allograft bone product loaded with either vancomycin or tobramycin $[32,33]$. The available release profile of the OSTEOmycin $^{\mathrm{Tm}}$ products [34] made it possible to estimate concentration.

\section{Results}

All four tested strains in this study were found susceptible to the tested antibiotics. The vancomycin MIC for both $S$. aureus strains was determined to be $1.25 \mathrm{mg} \mathrm{L}^{-1}$, which is lower than breakpoint $\left(2 \mathrm{mg} \mathrm{L}^{-1}\right)$ for S. aureus. Likewise, the tobramycin MIC for both P. aeruginosa 
Table 1 MBEC values of vancomycin for S. aureus found in a few studies. Please note ATCC 29213 were tested in several studies with different MBEC values

\begin{tabular}{|c|c|c|c|c|c|c|}
\hline S. aureus strains & $\begin{array}{l}\mathrm{MIC} \\
\left(\mathrm{mg} \mathrm{L}^{-1}\right)\end{array}$ & $\begin{array}{l}\text { Challenge } \\
\text { medium }\end{array}$ & $\begin{array}{l}\text { Biofilm } \\
\text { age (h) }\end{array}$ & $\begin{array}{l}\text { Treatment duration } \\
\text { (hours) }\end{array}$ & Biofilm model & $\begin{array}{l}\mathrm{MBEC} \\
\left(\mathrm{mg} \mathrm{L}^{-1}\right)\end{array}$ \\
\hline ATCC 49230 & 2 & TSB & 24 & $24,72,120$ & 96-well microtiter plate & $>8000,>8000,2000[9]$ \\
\hline ATCC BAA1556 & 2 & TSB & 24 & $24,72,120$ & 96-well microtiter plate & $>8000,8000,2000[9]$ \\
\hline ATCC 6538P, MRSA 16 & $0.5,1$ & Not mentioned & 24 & 24 & Beads & $>2000[10]$ \\
\hline ATCC 29213, UOC18 & $1-2$ & $\mathrm{CaMHB}$ & 24 & $1-72$ & CBD & $>1024[11]$ \\
\hline ATCC 29213 & 1 & $\mathrm{CaMHB}$ & 24 & overnight & CBD & $>1024$ [12] \\
\hline ATCC 29213 & 1 & $\mathrm{MHB}$ & 48 & 24 & CBD & $>512$ [13] \\
\hline ATCC 35556 & 1 & $\mathrm{CaMHB}$ & 24 & 24 & CBD & $>256[14]$ \\
\hline ATCC 29213, ATCC 33591, VRS5 & $1-2$ & $\mathrm{CaMHB}$ & 24 & 24 & CBD & $>128[15]$ \\
\hline B341002, B346846 & $0.5-1$ & $\mathrm{CaMHB}$ & 24 & overnight & CBD & $128,64[16]$ \\
\hline Clinical isolates & $0.5-1$ & $\mathrm{CaMHB}$ & 18 & 24 & 96-well microtiter plate & $8-16[17]$ \\
\hline Clinical isolates & $0.5-1$ & $\mathrm{CaMHB}$ & 18 & 24 & 96-well microtiter plate & $4-32[18]$ \\
\hline $\begin{array}{l}40 \text { MRSA } \\
\text { isolates }\end{array}$ & 1 & TSB & 24 & overnight & CBD & $1-64$ [19] \\
\hline
\end{tabular}

strains was $0.63 \mathrm{mg} \mathrm{L}^{-1}$, which is lower than breakpoint ( $4 \mathrm{mg} \mathrm{L}^{-1}$ ) for $P$. aeruginosa according to Clinical breakpoints - bacteria (v 9.0) in European Committee on Antimicrobial Susceptibility Testing (http://www.eucast. org/fileadmin/src/media/PDFs/EUCAST_files/Breakpoin t_tables/v_9.0_Breakpoint_Tables.pdf).

\section{Influence of biofilm age}

Biofilm growth is dynamic and mature biofilms are thought to be more antibiotic tolerant. In this study biofilms grew for $24 \mathrm{~h}$ or $72 \mathrm{~h}$ first and then were subjected to antibiotics challenge for different duration. It was found that the number of colony forming units (CFUs) were higher for $72 \mathrm{~h}$ biofilms than for $24 \mathrm{~h}$ biofilms by up to $1-\log$ difference $(P<0.01$, Figures $S 1$ and $\mathrm{S} 2)$. Additionally, $72 \mathrm{~h}$ biofilms were more difficult to eradicate than $24 \mathrm{~h}(P<0.001)$ as shown in Figs. 1 and 2 . It is important to stress that each data point in Figs. 1, 2 and 3 represents results for a minimum of 20 replicates from two independent experiments. Instead of MBEC value which defines complete killing of biofilms, biofilm survival ratio was chosen to present the percentage of replicates survived after treatment. The reason is that biofilm eradication was different among the replicates and a single MBEC value could not provide the information.

For complete killing of 24h DSM 110939 biofilms in TSB medium, i.e. MBEC, exposure of the biofilms with a minimum of $1000 \mathrm{mg} \mathrm{L}^{-1}$ of vancomycin for 4 days or $100 \mathrm{mg} \mathrm{L}^{-1}$ for 7 days was required (Fig. 1a), whereas some $72 \mathrm{~h}$ biofilms still survived even with $3000 \mathrm{mg} \mathrm{L}^{-1}$ of vancomycin after 7 days (Fig. 1b). In CaMHB medium it required $10 \mathrm{mg} \mathrm{L}^{-1}$ of vancomycin for 7 days to remove 24h DSM 110939 biofilms (Fig. 1c) and 10-fold more for $72 \mathrm{~h}$ biofilms (Fig. 1d).

In the case of strain PA14, a minimum of $10 \mathrm{mg} \mathrm{L}^{-1}$ of tobramycin killed almost all $24 \mathrm{~h}$ biofilms in TSB media regardless of exposure duration (Fig. 2a) while for $72 \mathrm{~h}$ biofilms $80 \mathrm{mg} \mathrm{L}^{-1}$ of tobramycin for at least 2 days was needed (Fig. 2b). In CaMHB medium, complete killing of $24 \mathrm{~h}$ biofilms was achieved with $5 \mathrm{mg} \mathrm{L}^{-1}$ of tobramycin regardless of exposure duration (Fig. 2c), while it required more than $10 \mathrm{mg} \mathrm{L}^{-1}$ for $72 \mathrm{~h}$ biofilms when the treatment was shorter than 7 days (Fig. 2d).

\section{Media}

Biofilm formation depends on many factors including nutrient availability. The main nutrients in both TSB

Table 2 MBEC values of tobramycin for $P$. aeruginosa in a few studies

\begin{tabular}{|c|c|c|c|c|c|c|}
\hline Strains & $\mathrm{MIC}\left(\mathrm{mg} \mathrm{L}^{-1}\right)$ & Challenge media & $\begin{array}{l}\text { Biofilm inoculation } \\
\text { (hours) }\end{array}$ & $\begin{array}{l}\text { Treatment duration } \\
\text { (hours) }\end{array}$ & Biofilm model & $\operatorname{MBEC}\left(\mathrm{mg} \mathrm{L}^{-1}\right.$ \\
\hline ATCC 27853 & $0.25-16$ & CaMHB & 24 & $1,2,4$ & 96-well microtiter plate & $160-2560[20]$ \\
\hline ATCC 27853 & 0.25 & TSB & 24 & $24,72,120$ & 96-well microtiter plate & $2000, \leq 250, \leq 250[9]$ \\
\hline Strain K (PAK) & Not tested & LB & 72 & 18 & 96-well microtiter plate & $200-1600[21]$ \\
\hline PAO1 & $<2$ & CaMHB & 6 & $16-20$ & CBD & $64[22]$ \\
\hline ATCC 27853 & 0.5 & CaMHB & 24 & overnight & CBD & 2 [12] \\
\hline
\end{tabular}




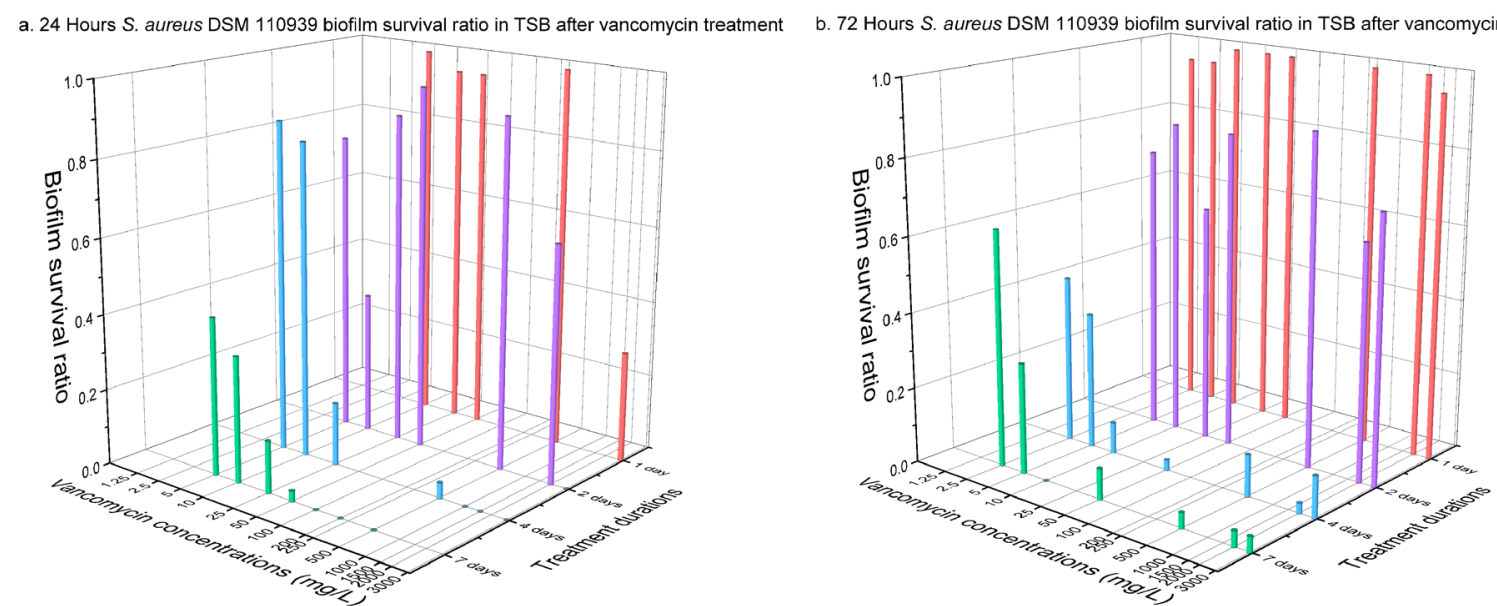

c. 24 Hours S. aureus DSM 110939 biofilm survival ratio in CAMHB after vancomycin treatment d. 72 Hours S. aureus DSM 110939 biofilm survival ratio in CAMHB after vancomycin treatment
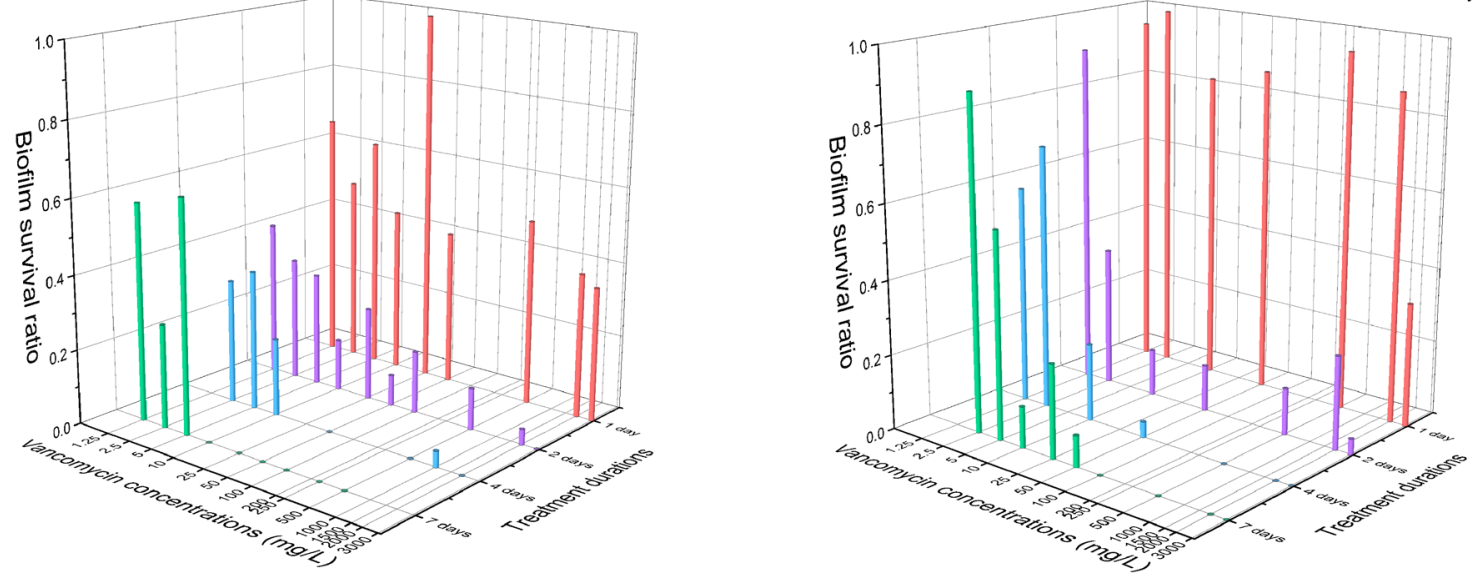

Fig. 1 S. aureus DSM 110939 biofilm survival ratio after vancomycin treatment. Biofilms of S. aureus DSM 110939 were grown for 24 h or 72 h in TSB or CaMHB medium followed by vancomycin treatment for 1, 2, 4 or 7 days. Each data point contained at least 20 replicates conducted at two occasions

and CaMHB media are amino acids. In addition, TSB contains glucose $\left(2.5 \mathrm{~g} \mathrm{~L}^{-1}\right)$ while CaMHB has starch $\left(1.5 \mathrm{~g} \mathrm{~L}^{-1}\right)$. The number of CFUs in the biofilms growing in these two media were different $(P<0.05$, Figure S1 and S2). On average, slightly more CFUs were found in biofilms growing in CaMHB than TSB, except $72 \mathrm{~h}$ PA14 biofilms.

When challenged with antibiotics, biofilms were more difficult to kill in TSB than in CaMHB. For 24 h DSM 110939 biofilms (Fig. 1a and c), seven-day treatment with $100 \mathrm{mg} \mathrm{L}^{-1}$ and $10 \mathrm{mg} \mathrm{L}^{-1}$ of vancomycin were required to kill all biofilms in TSB and CaMHB media, respectively. For $72 \mathrm{~h}$ DSM 110939 biofilms, none of the vancomycin treated achieved complete killing in TSB medium, while $100 \mathrm{mg} \mathrm{L}^{-1}$ of vancomycin removed all biofilms after 7 days exposure in CaMHB (Fig. $1 \mathrm{~b}$ and d). For all four treatment duration, $24 \mathrm{~h}$ PA14 biofilms, four-fold more tobramycin was needed in TSB than in CaMHB (10 and $2.5 \mathrm{mg} \mathrm{L}^{-1}$, respectively) for near complete killing (Fig. 2a and c), while for $72 \mathrm{~h}$ biofilms, two-fold more tobramycin was required $\left(80 \mathrm{mg} \mathrm{L}^{-1}\right.$ in TSB and $40 \mathrm{mg} \mathrm{L}^{-1}$ in CaMHB) (Fig. $2 \mathrm{~b}$ and d).

\section{Antibiotics exposure time}

Extending vancomycin exposure time from 1 to 4 days reduced survival ratio of DSM 110939 biofilm in TSB (Fig. 1a and b, Table 3) and CaMHB media (Fig. 1c and d, Table 3). Prolonging treatment from 4 to 7 days showed no further killing except $24 \mathrm{~h}$ biofilms in TSB (Table 3). Increased killing by prolonging vancomycin exposure was also found for S. aureus ATCC 49230 biofilms (Fig. 3a).

In contrast to vancomycin, tobramycin is known to exhibit concentration-dependent bactericidal activity [35]. Removal efficacy of $24 \mathrm{~h} \mathrm{P}$. aeruginosa PA14 biofilm was not enhanced when duration was extended (Fig. 2a and c, Table 4). However, increasing killing was indicated for $72 \mathrm{~h}$ PA14 biofilms (Fig. 2b and d, Table 4) 

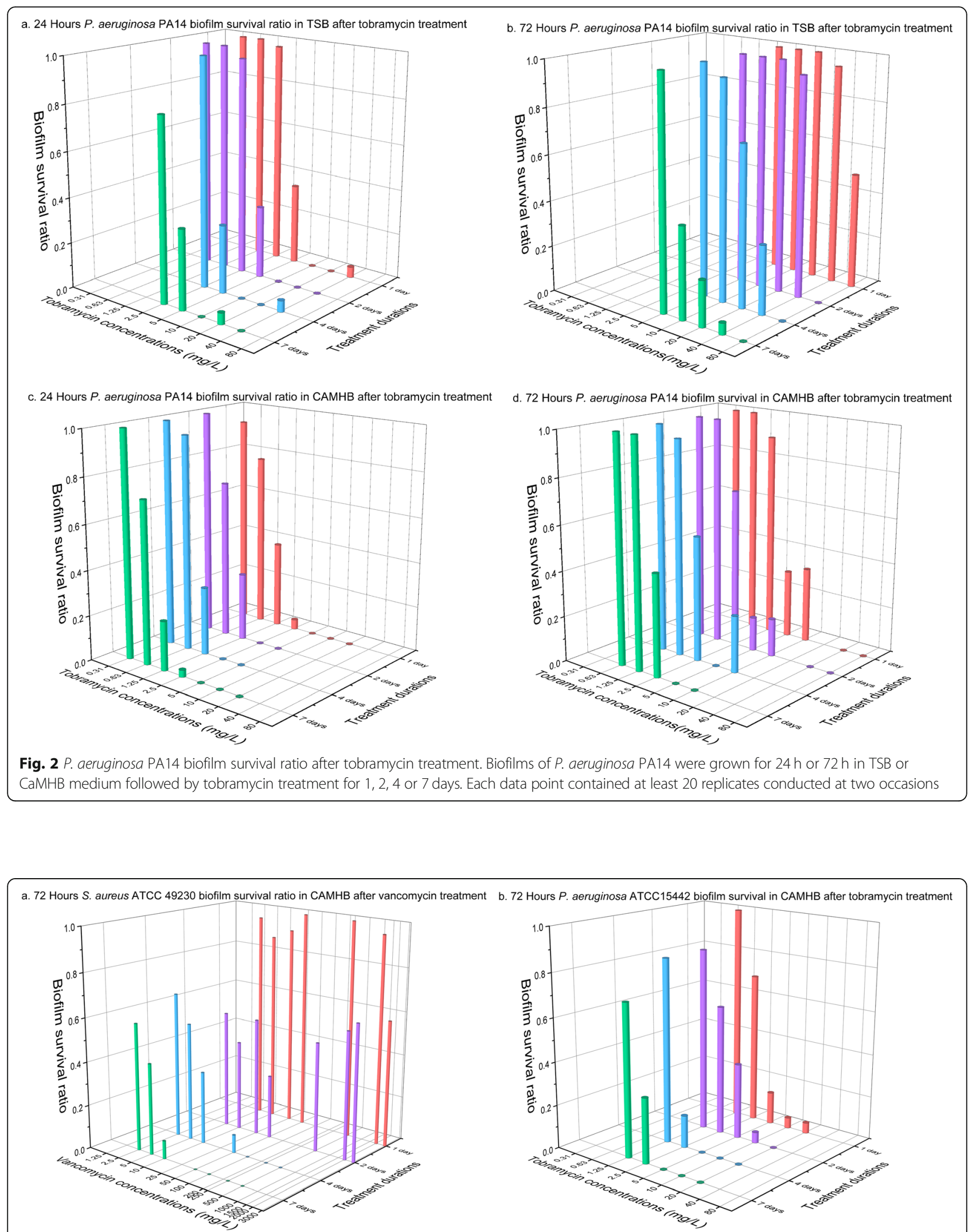

Fig. 3 Survival ratio of $72 \mathrm{~h}$ S. aureus ATCC 49230 biofilms after vancomycin treatment (a) and $72 \mathrm{~h}$ P. aeruginosa ATCC 15442 biofilm after tobramycin treatment (b). Each data point contained at least 20 replicates conducted at two occasions 
Table $3 P$-values for difference between S. aureus DSM 110939 biofilm survival ratio after vancomycin treatment of different durations. ${ }^{* *}$ indicates $P<0.001$

\begin{tabular}{|c|c|c|c|c|c|c|c|c|c|}
\hline \multirow[b]{2}{*}{ Biofilm age (hours) } & \multirow[b]{2}{*}{ Treatment durations (days) } & \multicolumn{4}{|c|}{ TSB } & \multicolumn{4}{|c|}{$\mathrm{CaMHB}$} \\
\hline & & 1 & 2 & 4 & 7 & 1 & 2 & 4 & 7 \\
\hline \multirow[t]{4}{*}{24} & 1 & - & $* *$ & $* *$ & $* *$ & - & $* *$ & $* *$ & $* *$ \\
\hline & 2 & & - & $* *$ & $* *$ & & - & 0.110 & 0.251 \\
\hline & 4 & & & - & $* *$ & & & - & 0.790 \\
\hline & 7 & & & & - & & & & - \\
\hline \multirow[t]{4}{*}{72} & 1 & - & $* *$ & $* *$ & $* *$ & - & $* *$ & $* *$ & $* *$ \\
\hline & 2 & & - & $* *$ & $* *$ & & - & 0.220 & 0.027 \\
\hline & 4 & & & - & 0.578 & & & - & 0.391 \\
\hline & 7 & & & & - & & & & - \\
\hline
\end{tabular}

as well as for $72 \mathrm{~h} P$. aeruginosa ATCC 15442 biofilms (Fig. 3b).

\section{Strains}

The two $S$. aureus strains have the same vancomycin MIC value. Although the necessary concentration of vancomycin for biofilm eradication differed slightly, the same tendency is indicated for both strains that prolonged vancomycin treatment eradicated more biofilms. Similarly, the two $P$. aeruginosa strains have the same tobramycin MIC value and extended tobramycin treatment lowered MBEC values for $72 \mathrm{~h}$ biofilms for both strains.

\section{OSTEOmycin ${ }^{\text {TM }}$}

Both $72 \mathrm{~h}$ and $168 \mathrm{~h}$ biofilms were challenged with OSTEOmycin $^{\text {Tw }}$ for one, two, four, and seven days (in total eight conditions). All PA14 biofilms were cleared after 1 day exposure to OSTEOmycin $\mathrm{T}^{\mathrm{Tm}}$ and remained sterile after 7 days exposure. All S. aureus ATCC 49230 biofilms were eradicated except that three replicates of $72 \mathrm{~h}$ biofilms survived 2 days treatment.

\section{Discussion}

\section{Biofilm age}

Several biofilm models have been developed, each with many experimental parameters that can be adjusted. This flexibility inevitably makes it difficult to compare results obtained with varying conditions chosen in different studies. In the current study we confirmed previous findings that mature biofilm have reduced antibiotics susceptibility compared with young biofilms [36-39]. However, no definition of young and mature biofilm has been universally adopted. In the case of $P$. aeruginosa, some considered $4 \mathrm{~h}$ biofilm as young and $24 \mathrm{~h}$ as mature [40], while others considered $24 \mathrm{~h}$ as young and 12 days biofilm as mature [38]. Similarly, $6 \mathrm{~h} S$. aureus biofilm was considered as young and $24 \mathrm{~h}$ as mature [41], whereas some considered 7 days old biofilm as mature [42]. The inconsistency in the different biofilm studies underlines the need for a form of consensus definition and a simple way to measure maturity. The textbook version of biofilm formation involves bacterial initial attachment to a solid surface, the formation of microcolonies on the surface, and finally differentiation of microcolonies into exopolysaccharide-encased, mature biofilms. However, studies often assume the

Table $4 P$-values for difference between $P$. aeruginosa $P A 14$ biofilm survival ratio after tobramycin treatment of different durations. * indicates $P<0.01$ and ${ }^{* *}$ indicates $P<0.001$

\begin{tabular}{|c|c|c|c|c|c|c|c|c|c|}
\hline \multirow[b]{2}{*}{ Biofilm age (hours) } & \multirow[b]{2}{*}{ Treatment durations (days) } & \multicolumn{4}{|c|}{ TSB } & \multicolumn{4}{|c|}{$\mathrm{CaMHB}$} \\
\hline & & 1 & 2 & 4 & 7 & 1 & 2 & 4 & 7 \\
\hline \multirow[t]{4}{*}{24} & 1 & - & 0.553 & 0.188 & 0.578 & - & 0.042 & 0.535 & 0.309 \\
\hline & 2 & & - & 0.220 & 0.518 & & - & * & 0.218 \\
\hline & 4 & & & - & 0.101 & & & - & 0.113 \\
\hline & 7 & & & & - & & & & - \\
\hline \multirow[t]{4}{*}{72} & 1 & - & * & $* *$ & $* *$ & - & 0.016 & $* *$ & $* *$ \\
\hline & 2 & & - & $* *$ & $* *$ & & - & 0.128 & * \\
\hline & 4 & & & - & $* *$ & & & - & 0.233 \\
\hline & 7 & & & & - & & & & - \\
\hline
\end{tabular}


maturity of the biofilm without looking into the structure of the biofilms or even CFUs of biofilm. In the case of MIC testing, a crucial parameter is inoculum size which is set to be $5 \times 10^{5} \mathrm{CFU} \mathrm{mL}^{-1}$. It is because MIC values can increase concurrently with increasing number of CFUs [43].

The current study treated $24 \mathrm{~h}$ biofilms as young and $72 \mathrm{~h}$ as mature. The CFU per biofilm shown in Figure S1 and $\mathrm{S} 2$ indicated continuous growth in cell number after $24 \mathrm{~h}$ for up to $1-\log$. In batch culture, bacterial growth curve defines the different stages of planktonic culture growth. Similarly, the biofilm formation curves can be established for each strain and growth condition. It was shown previously [12] that using CBD the number of $E$. coli ATCC 25922 and $P$. aeruginosa ATCC 27853 continuously increased over $24 \mathrm{~h}$ while the growth of $S$. aureus stagnated after $7 \mathrm{~h}$ under the same condition. As the growth phase of the biofilm influences antimicrobial susceptibility, it is therefore important to construct the biofilm growth curve for each strain under the chosen conditions.

\section{Growth media}

Biofilm eradication was found different with the two media (Fig. 1 and Fig. 2). Different composition of media is reported to change the activity of antibiotics [44-46]. The $\mathrm{Ca}^{2+}$ and $\mathrm{Mg}^{2+}$ ions in CaMHB media are required for a correct antimicrobial susceptibility testing because those ions reflect the divalent cation concentration in human blood [43, 47-49]. Neither of the two tested media, TSB and CaMHB, resembles in vivo conditions. However, use of CaMHB makes it possible to compare with MIC results, while TSB has been frequently used in other publications (Tables 1 and 2). Other media such as brain-heart infusion broth [50], TSB supplemented with glucose [51], LB [21], and chemically defined media such as basal medium 2 and M9 minimal media [52] have also been used in studies. The choice of media is known to affect biofilm formation [53, 54], but a standardized medium to assess the activity of antibiofilm agents has not been established. It is difficult to standardize because the in vivo environment of biofilm infections varies depending on the location of the infection, hence the optimal medium should be developed for each infection, for example, medium supplemented with mucin for studying cystic fibrosis lung infection [55], or saliva containing medium for studying oral biofilms [56], or human urine for urinary tract infections $[57,58]$. Besides nutrient source, in vivo conditions are far more complex with presence of immune systems and varying oxygen level etc., the antibiotics concentration needed for biofilm eradication will most likely be different from in vitro results. For comparison across different studies, a simple and widely available culture medium is suitable, but for estimation of in vivo biofilm killing host factors in form of, for example, serum, plasma, or blood should be included in testing medium.

\section{Antibiotics exposure time}

Vancomycin displayed a time-dependent eradication of $S$. aureus biofilms (Table 2) which has been demonstrated in other studies $[42,59,60]$. Post et al. have shown continuous reduction of viable $S$. aureus biofilm cells over 28 days [42]. This indicates that further killing could be possible by prolonging the antibiotic exposure time in the current study and complete eradication could be achieved at lower vancomycin concentration.

In contrast to vancomycin, tobramycin exhibits concentration-dependent activity [61-64]. The current study indicated that tobramycin displayed concentrationdependent activity for $24 \mathrm{~h}$ PA14 biofilms. However, increased killing of $72 \mathrm{~h}$ biofilms were observed with prolonged exposure. Castaneda et al. found increased biofilm antimicrobial susceptibility with increasing antimicrobial exposure time including tobramycin against $P$. aeruginosa biofilms [9], whereas Walters et al. only found little reduction in $P$. aeruginosa biofilm cell count with longer tobramycin treatment [65]. Futures studies are needed to investigate the time-dependency of tobramycin antibiofilm effect.

Regardless of the antimicrobials being time-dependent or concentration-dependent on planktonic bacteria, it may be different on biofilm cells because of the presence of biofilm matrix. Exposure time may play an important role in determination of killing effect, because the biofilm matrix may slow down antimicrobial penetration [66]. Therefore, a killing curve is much more informative than a definitive MBEC value determined at a fixed time point.

\section{OSTEOmycin ${ }^{\text {TM }}$}

Since the antibiotic concentration needed for biofilm eradication is far above the parenterally administrated levels, local delivery of antibiotics may achieve concentrations high enough for biofilm killing. In this study, OSTEOmycin $^{\text {Tw }}$ showed a strong biofilm eradication efficacy and completely removed biofilm in all tested conditions except three $72 \mathrm{~h} \mathrm{~S}$. aureus biofilms. OSTEOmycin $^{\text {tx }}$ is a product developed based on Winkler et al. 2000 [34]. According to the study, $1 \mathrm{~g}$ human cancellous bone impregnated with vancomycin released around 20, $000 \mathrm{mg} \mathrm{L}^{-1}$ vancomycin in $3 \mathrm{~mL}$ of $5 \%$ human albumin solution after 1 day and decreased to around $100 \mathrm{mg} \mathrm{L}^{-1}$ after 7 days. Accordingly, it implies that approximately $16,800 \mathrm{mg} \mathrm{L}^{-1}$ of vancomycin after 1 day and $84 \mathrm{mg} \mathrm{L}^{-1}$ after 7 days were released with the applied amount in this study. When impregnated with tobramycin, it 
released more than $10,000 \mathrm{mg} \mathrm{L}^{-1}$ tobramycin after 1 day and decreased to around $30 \mathrm{mg} \mathrm{L}^{-1}$ after 7 days [34], suggesting $6600 \mathrm{mg} \mathrm{L}^{-1}$ of vancomycin after 1 day and $19.8 \mathrm{mg} \mathrm{L}^{-1}$ were released after 7 days with the applied amount in this study. These concentrations are much higher than the MBEC values found in Figs. 1 and 2 , which likely explains the high efficacy. This indicates that prolonged antibiotics treatment may not be necessary when sufficiently high concentration of antibiotics is administered in the beginning of treatment. OSTEOmycin was also shown to be efficient for local treatment of osteomyelitis in the clinic although recurrence may still occur in complex cases within an unknown period of time [33]. The limitation of this study is that OSTEOmycin $^{\text {nx }}$ was not tested in a medium resembling the nutrient composition in the bone under in vivo like conditions, and more clinically used or candidate antibiofilm products for osteomyelitis could have been evaluated, such as antibiotics impregnated cement or hydrochlorous acid. Ideally, the in vitro effect of these antibiofilm products could be compared to clinical outcome to validate the assay. Assays developed in such as way could be used to guide the dose of antibiotics for clinical application.

In this study, the used conditions (nutrient rich media, $\mathrm{pH}$, atmospheric oxygen level, shear, biofilm growth in static system, mono species biofilm etc.) were not specific for a distinct biofilm infection and more suitable for initial testing of antibiofilm product. It was by no means meant as a standardization or guideline for clinical application. The purpose was to raise the awareness that biofilm eradication depends on many factors, including the ones mentioned here, but also $\mathrm{pH}$, oxygen level, temperature, shear, and complicated by polymicrobial community interactions and the presence of human factors such as the human immune systems. For specific biofilm infections, we think it is necessary to develop assays with in vivo like environment and validate obtained results by comparing with clinical outcome.

\section{Conclusion}

This study showed biofilm removal efficacy was influenced by media, biofilm age and antibiotics treatment duration. It is therefore necessary to take these parameters into consideration when designing experiments. We recommend choosing the conditions most similar to the in vivo situation and explaining the rationale when reporting. This study also showed that in vitro biofilms were possible to be eradicated when treated with long-term high concentrations of antibiotics. This finding needs to be confirmed by in vivo studies.

\section{Methods}

Bacterial strains, growth media and antibiotics

S. aureus strains DSM 110939 [28] and ATCC 49230 were tested with vancomycin (Sigma-Aldrich). P. aeruginosa strains PA14 and ATCC 15442 were tested with tobramycin (Sigma-Aldrich). Both tryptic soy broth (TSB) (Sigma-Aldrich) and cation-adjusted Mueller Hinton broth (CaMHB) (Sigma-Aldrich) media were employed in susceptibility testing.

\section{Minimum inhibitory concentration (MIC) determined by the broth microdilution method}

The broth microdilution method was used to determine the MIC of each strain according to the procedures described in Wiegand et al. [43]. Briefly, each strain was inoculated on TSB agar plate for $24 \mathrm{~h}$. Then five wellisolated colonies were selected and inoculated in a 50 $\mathrm{mL}$ tube with $20 \mathrm{~mL}$ CaMHB until the OD600 value of the culture reached around 0.6. The culture was diluted to approximately $1 \times 10^{6}$ colony-forming unit (CFU) $\mathrm{mL}^{-1}$. Then, $100 \mu \mathrm{l}$ of the diluted culture was added into each well of a 96-well-plate containing $100 \mu \mathrm{l}$ of antibiotics at concentrations from 0.31 to $80 \mathrm{mg} \mathrm{L}^{-1}$ of tobramycin or from 1.25 to $3000 \mathrm{mg} \mathrm{L}^{-1}$ of vancomycin). The plate was covered and inoculated at $37^{\circ} \mathrm{C}$ with shaking at $150 \mathrm{rpm}$ for $24 \mathrm{~h}$. After that, OD595 of each well was measured by Infinite F200 Pro (Tecan Group Ltd., Switzerland) to determine MIC.

\section{Biofilm antibiotics susceptibility testing by Calgary biofilm device (CBD)}

CBD [67] was used to grow biofilms. An illustration of the experimental procedure is given in Figure S3. Briefly, biofilms were formed by immersing the pegs of a microtiter lid (Nunc $\left.{ }^{\text {Tw }} 445497\right)$ into the biofilm growth microtiter plate, $150 \mu \mathrm{l}$ of the diluted culture containing $10^{4}$ CFU was added into the wells of 96 well microtiter plate (Thermo Fisher Scientific) and then covered with peg lid The biofilms were allowed to grow in TSB or CaMHB media at $37^{\circ} \mathrm{C}$ with shaking at $150 \mathrm{rpm}$ for $24 \mathrm{~h}$ or $72 \mathrm{~h}$. After incubation, the lid with biofilms was transferred to a rinse plate containing $200 \mu \mathrm{l}$ saline in each well and incubated for $1 \mathrm{~min}$. The rinsed lid was then transferred to a challenge plate containing $200 \mu \mathrm{l}$ antibiotics solution in each well. The antibiotics were prepared in the media used for growing biofilms. The plates were challenged for $24,48,96$ or $168 \mathrm{~h}$ at $37^{\circ} \mathrm{C}$ with shaking at $150 \mathrm{rpm}$. After challenged in the antibiotics solution, the lid containing biofilms was rinsed twice with fresh saline each time and then transferred to a recovery plate containing $200 \mu \mathrm{l}$ sterile media followed by sonication at $40 \mathrm{KHz}$ for 5 min.

After removal of the lid, the recovery plate was inoculated for another $24 \mathrm{~h}$ at $37^{\circ} \mathrm{C}$ with shaking at $150 \mathrm{rpm}$ 
and OD595 measured by Infinite F200 Pro to determine the biofilm removal efficacy. All tests were repeated at least on two occasions with minimum 10 replicates each time. Percentage of the surviving replicates was calculated and presented as biofilm survival ratio.

\section{Biofilm eradication by OSTEOmycin ${ }^{\mathrm{TM}}$}

OSTEOmycin $^{\text {th }}$ samples were obtained from European Cell and Tissue Bank. Two clinical strains S. aureus ATCC 49230 and $P$. aeruginosa PA14 were chosen for this test. Seventy-two hours (3-days) or $168 \mathrm{~h}$ (7-days) biofilms were challenged with OSTEOmycin ${ }^{\text {tix }}$ for $1,2,4$ or 7 days following the method described above. S. aureus ATCC 49230 biofilms were challenged with $280 \mathrm{~g} \mathrm{~L}^{-1}$ OSTEOmycin $\mathrm{V}^{\mathrm{st}}$ in CaMHB, while P. aeruginosa PA14 biofilms were subjected to $220 \mathrm{~g} \mathrm{~L}^{-1}$ OSTEOmycin $\mathrm{T}^{\mathrm{Tm}}$.

\section{Statistics analysis}

ANOVA was used to calculate the difference between biofilm formation on CBD pegs. Binary logistic regression model was used to compare biofilm removal efficacy under different conditions.

\section{Supplementary information}

Supplementary information accompanies this paper at https://doi.org/10. 1186/s12866-020-01947-9.

Additional file 1: Figure S1. S. aureus biofilm formation on CBD. After 24 or $72 \mathrm{~h}$ of growth, biofilms were removed from the pegs, transferred into the recovery plate and harvested by sonication. Six random wells of each row were selected for CFU count, in total 48 wells per plate. The number of CFUs per peg were different under different conditions. Generally 3 days incubation resulted in more CFUs per peg. Figure S2. P. aeruginosa PA14 biofilm formation on CBD. After 24 or $72 \mathrm{~h}$ of growth, biofilms were removed from the pegs, transferred into the recovery plate and harvested by sonication. Six random wells of each row were selected for CFU count, in total 48 wells per plate. The number of CFUs per peg were different under different conditions. Generally 3 days incubation resulted in more CFUs per peg. Figure S3. Flow diagram of the MBEC assay.

\section{Abbreviations}

CaMHB: Cation-adjusted Mueller Hinton broth; CBD: Calgary biofilm device; CFU: Colony forming units; MBEC: Minimum biofilm eradication concentration; MBC: Minimum bactericidal concentration; MIC: Minimum inhibitory concentration; TSB: Tryptic soy broth

\section{Acknowledgements}

We thank technician Susanne Bielidt for her assistance in the laboratory.

\section{Authors' contributions}

TRT, HW and YX designed the study, XC performed the experimental work. $X C$, TRT, and $Y X$ performed data analysis, $X C$, TRT and $Y X$ drafted the manuscript. All authors were involved in revising the manuscript. The author(s) read and approved the final manuscript.

\section{Funding}

This study was supported by Det Obelske Familiefond (grant no 27751). The foundation was not involved in the design of the study and collection, analysis, and interpretation of data and in writing the manuscript.
Availability of data and materials

The datasets used and/or analysed during the current study are available from the corresponding author on reasonable request.

Ethics approval and consent to participate

Not applicable.

Consent for publication

Not applicable.

\section{Competing interests}

The authors declare that they have no competing interests.

\section{Author details}

${ }^{1}$ Center for Microbial Communities, Aalborg University, Aalborg East, Denmark. 'Life Science Division, Danish Technological Institute, Aarhus, Denmark. ${ }^{3}$ Osteitis Centre, Privatklinik Döbling, Vienna, Austria.

Received: 27 March 2020 Accepted: 13 August 2020

Published online: 24 August 2020

\section{References}

1. Burmølle M, Thomsen TR, Fazli M, Dige I, Christensen L, Homøe P, Tvede M, Nyvad B, Tolker-Nielsen T, Givskov M, Moser C, Kirketerp-Møller K, Johansen HK, Høiby N, Jensen PØ, Sørensen SJ, Bjarnsholt T. Biofilms in chronic infections - a matter of opportunity - monospecies biofilms in multispecies infections. FEMS Immunol Med Microbiol. 2010;59:324-36.

2. Flemming H-C, Wingender J. The biofilm matrix. Nat Rev Microbiol. 2010;8: 623-33.

3. Watnick P, Kolter R. Biofilm, City of microbes. J Bacteriol. 2000;182:2675-9.

4. Costerton JW. Introduction to biofilm. Int J Antimicrob Agents. 1999;11:217-21.

5. Fux CA, Stoodley P, Hall-Stoodley L, Costerton JW. Bacterial biofilms: a diagnostic and therapeutic challenge. Expert Rev Anti-Infect Ther. 2003;1: 667-83.

6. Alhede M, Bjarnsholt T, Jensen PØ, Phipps RK, Moser C, Christophersen L, Christensen LD, van Gennip M, Parsek M, Høiby N, Rasmussen TB, Givskov M. Pseudomonas aeruginosa recognizes and responds aggressively to the presence of polymorphonuclear leukocytes. Microbiology. 2009;155:3500-8.

7. Bjarnsholt $T$, Jensen $P \varnothing$, Burmølle $M$, Hentzer $M$, Haagensen JAJ, Hougen HP, Calum H, Madsen KG, Moser C, Molin S, Høiby N, Givskov M. Pseudomonas aeruginosa tolerance to tobramycin, hydrogen peroxide and polymorphonuclear leukocytes is quorum-sensing dependent. Microbiology. 2005:151:373-83.

8. Wilkins M, Hall-Stoodley L, Allan RN, Faust SN. New approaches to the treatment of biofilm-related infections. J Infect. 2014:69:S47-52.

9. Castaneda P, McLaren A, Tavaziva G, Overstreet D. Biofilm antimicrobial susceptibility increases with antimicrobial exposure time. Clin Orthop Relat Res. 2016;474(7):1659-64

10. Meije $Y$, Almirante B, Del Pozo JL, Martín MT, Fernández-Hidalgo N, Shan A, Basas J, Pahissa A, Gavaldà J. Daptomycin is effective as antibiotic-lock therapy in a model of Staphylococcus aureus catheter-related infection. J Inf Secur. 2014:68:548-52.

11. Kostenko V, Ceri H, Martinuzzi RJ. Increased tolerance of Staphylococcus aureus to vancomycin in viscous media. FEMS Immunol Med Microbiol. 2007:51:277-88

12. Ceri H, Olson ME, Stremick C, Read RR, Morck D, Buret A. The Calgary biofilm device: new technology for rapid determination of antibiotic susceptibilities of bacterial biofilms. J Clin Microbiol. 1999:37:1771-6.

13. Coraça-Hubér DC, Fille M, Hausdorfer J, Pfaller K, Nogler M. Evaluation of MBEC $^{\text {TM}}{ }_{-}$HTP biofilm model for studies of implant associated infections. J Orthop Res. 2012;30:1176-80

14. LaPlante KL, Mermel LA. In vitro activities of Telavancin and Vancomycin against biofilm-producing Staphylococcus aureus, S. epidermidis, and enterococcus faecalis strains. Antimicrob Agents Chemother. 2009;53:3166-9.

15. Belley A, Neesham-Grenon E, McKay G, Arhin FF, Harris R, Beveridge T, Parr TR, Moeck G. Oritavancin kills stationary-phase and biofilm Staphylococcus aureus cells in vitro. Antimicrob Agents Chemother. 2009:53:918-25.

16. LaPlante KL, Woodmansee $\mathrm{S}$. Activities of Daptomycin and Vancomycin alone and in combination with rifampin and gentamicin against biofilmforming methicillin-resistant Staphylococcus aureus isolates in an 
experimental model of endocarditis. Antimicrob Agents Chemother. 2009; 53:3880-6.

17. Antunes ALS, Trentin DS, Bonfanti JW, Pinto CCF, Perez LRR, Macedo AJ, Barth AL. Application of a feasible method for determination of biofilm antimicrobial susceptibility in staphylococci. APMIS. 2010;118:873-7.

18. Antunes ALS, Bonfanti JW, Perez LRR, Pinto CCF, de Freitas ALP, Macedo AJ, Barth AL. High vancomycin resistance among biofilms produced by Staphylococcus species isolated from central venous catheters. Mem Inst Oswaldo Cruz. 2011;106:51-5

19. Rose WE, Poppens PT. Impact of biofilm on the in vitro activity of vancomycin alone and in combination with tigecycline and rifampicin against Staphylococcus aureus. J Antimicrob Chemother. 2009;63:485-8.

20. Dosler S, Karaaslan E. Inhibition and destruction of Pseudomonas aeruginosa biofilms by antibiotics and antimicrobial peptides. Peptides. 2014;62:32-7.

21. Reighard KP, Schoenfisch MH. Antibacterial action of nitric oxidereleasing chitosan oligosaccharides against Pseudomonas aeruginosa under aerobic and anaerobic conditions. Antimicrob Agents Chemother. 2015;59:6506-13.

22. De Kievit TR, Parkins MD, Gillis RJ, Srikumar R, Ceri H, Poole K, Iglewski BH, Storey DG. Multidrug efflux pumps: expression patterns and contribution to antibiotic resistance in Pseudomonas aeruginosa biofilms. Antimicrob Agents Chemother. 2001;45:1761-70.

23. Macia MD, Rojo-Molinero E, Oliver A. Antimicrobial susceptibility testing in biofilm-growing bacteria. Clin Microbiol Infect. 2014;20:981-90.

24. Escudero-Sanchez R, Senneville E, Digumber M, Soriano A, Del Toro MD, Bahamonde A, Del Pozo JL, Guio L, Murillo O, Rico A, García-País MJ, Rodríguez-Pardo D, Iribarren JA, Fernández M, Benito N, Fresco G, Muriel A, Ariza J, Cobo J. Suppressive antibiotic therapy in prosthetic joint infections: a multicentre cohort study. Clin Microbiol Infect. 2020;26:499-505.

25. Rao N, Ziran BH, Lipsky BA. Treating osteomyelitis: antibiotics and surgery. Plast Reconstr Surg. 2011;127:177S.

26. Anagnostakos K. Therapeutic use of antibiotic-loaded bone cement in the treatment of hip and knee joint infections. J Bone Jt Infect. 2017;2:29-37.

27. Cochran AR, Ong KL, Lau E, Mont MA, Malkani AL. Risk of reinfection after treatment of infected Total knee Arthroplasty. J Arthroplast. 2016 31:156-61.

28. Xu Y, Maltesen RG, Larsen LH, Schønheyder HC, Le VQ, Nielsen JL, Nielsen $\mathrm{PH}$, Thomsen TR, Nielsen KL. In vivo gene expression in a Staphylococcus aureus prosthetic joint infection characterized by RNA sequencing and metabolomics: a pilot study. BMC Microbiol. 2016;16:80

29. Friedman L, Kolter R. Genes involved in matrix formation in Pseudomonas aeruginosa PA14 biofilms. Mol Microbiol. 2004;51:675-90.

30. Diaz De Rienzo MA, Stevenson PS, Marchant R, Banat IM. Effect of biosurfactants on Pseudomonas aeruginosa and Staphylococcus aureus biofilms in a BioFlux channel. Appl Microbiol Biotechnol. 2016;100:5773-9.

31. Rienzo MADD, Stevenson PS, Marchant R, Banat IM. Pseudomonas aeruginosa biofilm disruption using microbial surfactants. J Appl Microbiol. 2016;120:868-76.

32. Winkler H. Treatment of chronic orthopaedic infection. EFORT Open Rev. 2017;2:110-6.

33. Winkler $\mathrm{H}$, Haiden $\mathrm{P}$. Treatment of chronic bone infection. Oper Tech Orthop. 2016;26:2-11.

34. Winkler $\mathrm{H}$, Janata $\mathrm{O}$, Berger $\mathrm{C}$, Wein W, Georgopoulos A. In vitro release of vancomycin and tobramycin from impregnated human and bovine bone grafts. J Antimicrob Chemother. 2000;46:423-8.

35. Beringer PM, Vinks AA, Jelliffe RW, Shapiro BJ. Pharmacokinetics of tobramycin in adults with cystic fibrosis: implications for once-daily administration. Antimicrob Agents Chemother. 2000;44:809-13.

36. Tré-Hardy M, Macé C, Manssouri NE, Vanderbist F, Traore H, Devleeschouwer MJ. Effect of antibiotic co-administration on young and mature biofilms of cystic fibrosis clinical isolates: the importance of the biofilm model. Int J Antimicrob Agents. 2009;33:40-5.

37. Hengzhuang W, Wu H, Ciofu O, Song Z, Høiby N. Pharmacokinetics/ pharmacodynamics of Colistin and Imipenem on Mucoid and Nonmucoid Pseudomonas aeruginosa biofilms. Antimicrob Agents Chemother. 2011;55: 4469-74.

38. Nagant C, Tré-Hardy M, El-Ouaaliti M, Savage P, Devleeschouwer MJ, Dehaye J-P. Interaction between tobramycin and CSA-13 on clinical isolates of Pseudomonas aeruginosa in a model of young and mature biofilms. Appl Microbiol Biotechnol. 2010;88:251-63.
39. Ito A, Taniuchi A, May T, Kawata K, Okabe S. Increased antibiotic resistance of Escherichia coli in mature biofilms. Appl Environ Microbiol. 2009;75:4093-100.

40. Bowler LL, Zhanel GG, Ball TB, Saward LL. Mature Pseudomonas aeruginosa biofilms prevail compared to young biofilms in the presence of Ceftazidime. Antimicrob Agents Chemother. 2012;56:4976-9.

41. Wu S, Yang T, Luo Y, Li X, Zhang X, Tang J, Ma X, Wang Z. Efficacy of the novel oxazolidinone compound FYL-67 for preventing biofilm formation by Staphylococcus aureus. J Antimicrob Chemother. 2014;69:3011-9.

42. Post V, Wahl P, Richards RG, Moriarty TF. Vancomycin displays timedependent eradication of mature Staphylococcus aureus biofilms. J Orthop Res. 2017;35:381-8.

43. Wiegand I, Hilpert K, Hancock REW. Agar and broth dilution methods to determine the minimal inhibitory concentration (MIC) of antimicrobial substances. Nat Protoc. 2008;3:163-75.

44. Digranes A, Dibb WL, Benonisen E, Ostervold B. The in vitro activity of gentamicin, tobramycin and netilmicin against 500 clinical isolates of bacteria. A comparative study using three different test media. Acta Pathol Microbiol Immunol Scand B. 1983;91:135-9.

45. Cruz RC, Werneck SMC, Oliveira CS, Santos PC, Soares BM, Santos DA, Cisalpino PS. Influence of different media, incubation times, and temperatures for determining the MICs of seven antifungal agents against Paracoccidioides brasiliensis by microdilution. J Clin Microbiol. 2013;51:436-43.

46. Barry AL, Miller GH, Thornsberry C, Hare RS, Jones RN, Lorber RR, Ferraresi R, Cramer $C$. Influence of cation supplements on activity of netilmicin against Pseudomonas aeruginosa in vitro and in vivo. Antimicrob Agents Chemother. 1987;31:1514-8.

47. Nanavaty J, Mortensen JE, Shryock TR. The effects of environmental conditions on the in vitro activity of selected antimicrobial agents against < emphasis type $=$ "italic" $>$ Escherichia coli</emphasis $>$. Curr Microbiol. 1998;36: 212-5.

48. D'amato RF, Thornsberry C, Baker CN, Kirven LA. Effect of calcium and magnesium ions on the susceptibility of Pseudomonas species to tetracycline, gentamicin polymyxin B, and carbenicillin. Antimicrob Agents Chemother. 1975;7:596-600.

49. Rhomberg PR, Sader HS, Jones RN. Reproducibility of daptomycin MIC results using dry-form commercial trays with appropriate supplemental calcium content. Int J Antimicrob Agents. 2005;25:274-6.

50. Singh AK, Prakash P, Achra A, Singh GP, Das A, Singh RK. Standardization and classification of in vitro biofilm formation by clinical isolates of Staphylococcus aureus. J Glob Infect Dis. 2017;9:93-101.

51. Lade H, Park JH, Chung SH, Kim IH, Kim J-M, Joo H-S, Kim J-S. Biofilm formation by Staphylococcus aureus clinical isolates is differentially affected by glucose and sodium chloride supplemented culture media. J Clin Med. 2019:8:1853.

52. Haney EF, Trimble MJ, Cheng JT, Vallé Q, Hancock REW. Critical assessment of methods to quantify biofilm growth and evaluate Antibiofilm activity of host Defence peptides. Biomolecules. 2018;8:29.

53. Hancock V, Witsø IL, Klemm P. Biofilm formation as a function of adhesin, growth medium, substratum and strain type. Int J Med Microbiol. 2011;301: 570-6.

54. Wijesinghe G, Dilhari A, Gayani B, Kottegoda N, Samaranayake L, Weerasekera M. Influence of laboratory culture media on in vitro growth, adhesion, and biofilm formation of Pseudomonas aeruginosa and Staphylococcus aureus. Med Princ Pract. 2019;28:28-35.

55. Haley CL, Colmer-Hamood JA, Hamood AN. Characterization of biofilm-like structures formed by Pseudomonas aeruginosa in a synthetic mucus medium. BMC Microbiol. 2012;12:181.

56. Ahn S-J, Ahn S-J, Wen ZT, Brady LJ, Burne RA. Characteristics of biofilm formation by Streptococcus mutans in the presence of saliva. Infect Immun. 2008;76:4259-68.

57. Sm J, Me S. Proteus mirabilis biofilms and catheter-associated urinary tract infections. Virulence. 2011;2:460-5.

58. Hancock V, Ferrières L, Klemm P. Biofilm formation by asymptomatic and virulent urinary tract infectious Escherichia coli strains. FEMS Microbiol Lett. 2007;267:30-7.

59. Rybak MJ. The pharmacokinetic and pharmacodynamic properties of vancomycin. Clin Infect Dis. 2006:42(Suppl 1):S35-9.

60. Vandecasteele SJ, De Vriese AS, Tacconelli E. The pharmacokinetics and pharmacodynamics of vancomycin in clinical practice: evidence and uncertainties. J Antimicrob Chemother. 2013;68:743-8. 
61. Kapusnik JE, Hackbarth CJ, Chambers HF, Carpenter T, Sande MA. Single, large, daily dosing versus intermittent dosing of tobramycin for treating experimental pseudomonas pneumonia. J Infect Dis. 1988;158:7-12.

62. Craig WA, Ebert SC. Killing and regrowth of bacteria in vitro: a review. Scand J Infect Dis Suppl. 1990;74:63-70.

63. Vogelman B, Gudmundsson S, Leggett J, Turnidge J, Ebert S, Craig WA. Correlation of antimicrobial pharmacokinetic parameters with therapeutic efficacy in an animal model. J Infect Dis. 1988;158:831-47.

64. Leggett JE, Fantin B, Ebert S, Totsuka K, Vogelman B, Calame W, Mattie H, Craig WA. Comparative antibiotic dose-effect relations at several dosing intervals in murine pneumonitis and thigh-infection models. J Infect Dis. 1989;159:281-92.

65. Walters MC, Roe F, Bugnicourt A, Franklin MJ, Stewart PS. Contributions of antibiotic penetration, oxygen limitation, and low metabolic activity to tolerance of Pseudomonas aeruginosa biofilms to ciprofloxacin and tobramycin. Antimicrob Agents Chemother. 2003;47:317-23.

66. Stewart PS. Antimicrobial tolerance in biofilms. Microbiol. Spectr. 2015;3: 269-85.

67. Harrison JJ, Stremick CA, Turner RJ, Allan ND, Olson ME, Ceri H. Microtiter susceptibility testing of microbes growing on peg lids: a miniaturized biofilm model for high-throughput screening. Nat Protocols. 2010;5:123654.

\section{Publisher's Note}

Springer Nature remains neutral with regard to jurisdictional claims in published maps and institutional affiliations.

- fast, convenient online submission

- thorough peer review by experienced researchers in your field

- rapid publication on acceptance

- support for research data, including large and complex data types

- gold Open Access which fosters wider collaboration and increased citations

- maximum visibility for your research: over $100 \mathrm{M}$ website views per year

At $\mathrm{BMC}$, research is always in progress.

Learn more biomedcentral.com/submissions 